\title{
Rectal Polyp Caused by Schistosoma Haematobium
}

\author{
Nick Janssen ${ }^{1}$, Jeroen Heemskerk ${ }^{2}$, Arjan P. Willig ${ }^{3}$, Susan M. Toebosch ${ }^{1}$
}

1) Department of Gastroenterology, 2) Department of Surgery, 3) Department of Pathology, Laurentius Hospital, Roermond, The Netherlands
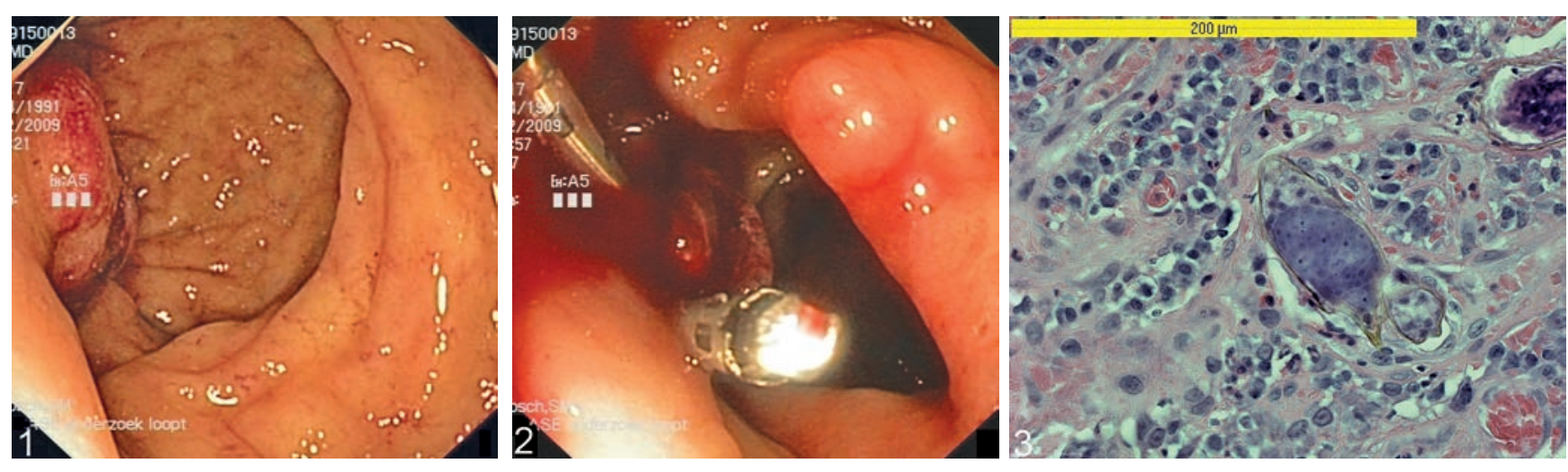

A 17-year Eritrean male presented with symptoms of rectal bleeding and three kilograms weight loss. Defecation pattern had not altered. Medical and family histories were not relevant.

Physical examination was unremarkable. Ileocolonoscopy evidenced a $3 \mathrm{~cm}$ flat lobed polyp in the distal rectum. Partial removal was performed using snare electrocoagulation (Figs. 1,2 ), which was complicated by an arterial bleeding. Attempts to achieve hemostasis endoscopically using electrocoagulation, adrenalin injection and haemoclips were unsuccessful. In the operating room under general anesthesia, the bleeding was stopped surgically using transanal applied resorbable stitches.

Histopathological examination of the specimen showed hyperplastic mucosa with infiltrates of granulomatous inflammation around schistosoma eggs with a sharp hook, suggesting Schistosoma Haematobium (Fig. 3). There were no signs of malignancy. The patient was treated with a single dose Praziquentel of 2400 milligrams. Three weeks postileocolonoscopy, there were no signs of ongoing rectal bleeding.

Schistosomiasis is a tropical disease caused by trematodes of the genus Schistosoma [1]. Five species generally cause infections in humans; S. Mansoni, S. Japonicum, S. Mekongi, $S$. Intercalatum generally infest the mesenteric and portal veins, and $S$. Haematobium mainly involves the venous plexus of the bladder, but can also be found in rectal venules [2-3]. Female adult worms produce and deposit eggs in the venules, which migrate toward the lumen of the intestine (Mansoni, S. Japonicum, S. Mekongi, S. Intercalatum) or the bladder and ureters (S. Haematobium), and are excreted with feces or urine, respectively. In S. Haematobium infestation, the ova present in the colonic mucosa rarely produce clinical disease. However, if the eggs cause excessive inflammatory response, this can lead to ulceration, pseudopolyposis, bleeding and sometimes colorectal stenosis $[4,5]$.
Despite the few reports in Western literature on rectal polyps caused by S. Haematobium, knowledge of this condition seems important. Expansion of intercontinental travelling and migration will most likely lead to an increase in presentation of this disease in Europe and Northern America. Recognition is crucial in order to achieve correct diagnosis and provide adequate medical care. This includes colonic inflammation, ulceration and diaphragm like strictures that are considered to be pathognomonic. Early recognition of its endoscopic aspects is of major importance for diagnosis and prevention of disease progression $[2,3]$.

Corresponding author: Nick Janssen; janssennicolaas@gmail.com

Conflicts of interest: None to declare.

\section{REFERENCES}

1. Gryseels B, Polman K, Clerinx J, Kestens L. Human Schistosomiasis. Lancet 2006;368:1106-1118.

2. Ross AG, Bartley PB, Sleigh AC, et al. Schistosomiasis. N Engl J Med 2002;346:1212-2020.

3. Delgrado J, Delgrado B, Sztarkier I, Baer A, Depsames R. Schistosomal rectal polyp - an unusual cause of rectal bleeding. Isr Med Assoc J 2004;6:114-115.

4. Bessa SM, Helmy I, Mekky F, Hamam M. Colorectal schistosomiasis: clinicopathologic study and management. Dis Colon Rectum 1979;22:390-395.

5. Atik FA, Lopes Filho GJ, Linhares Mde M, Seda Neto J, Mansur NS. Large intestine obstruction complicated with perforation: a rare manifestation of Schistosoma mansoni infection. Sao Paulo Med J 1998;116:17811783. 